ensifornis und Nabel, bei leereren Magen etwas oberhalb oder unter dem linken Rippenbogen (bei Längsschuitt) angelegt. Die Magenserosa wird auf einer moglichst kleinen Fläche durch fortlaufende, fünf bis sieben Stiche einbegreifende, feine Seidennaht mit Peritoneum parietale umsäumt. Dann - nach Bepudern des Operationsterrains mit irgendeinem Pulver - wird zwischen zwei Klemmpinzetten der Magen mit einem spitzen Messcr eroffnet und mittels eines gut $1 \mathrm{~cm}$ dicken, etwa $5-8 \mathrm{~cm}$ weit eingeführten Gummischlauchs mit einer auf den Boden leitenden Heberdrainage verbunden; es enpfiehlt sich, einen recht festen Schlauch zu nehmen, der nach Einfúgung des verbinden. den Glasstuckes nicht abknickt.

Der Schlauch gewährleistet eine permanente Entleerung des Magens. Die etwa - bei Zufuhr von Milch leicht - eintretende Verstopfung der Lichtung, auf die übrigens der Kranke meist sofort mit Gefühl der Völle oder Aufstoßen reagiert, beseitigt schnell eine Durchspülung von außen. Der Sclilauch bleibt mindestens bis zur völligen Regelung der Magen- und Darmtätigkeit liegelı. Lennander gebraucht den Witzelschen Schrägkanal, dessen Bildung einen wesentlich komplizicrteren Eingriff darstellt. Unsere ,einfache" Magenfistel läßt siclı bequcm in zehn Minuten anlegcn.

Schon auf dem Operationstisch erfolgt die erste Entleerung von Gas und zersetztem Mageninhalt, dann beginnt sofort die Zufuhr von Flüssigkeit per os in beliebiger Menge, soviel der Kranke nur will und nıag. Der psychische Einfluß auf ihn, der, von Durst gequält, auf jede Flüssigkeitsaufnalıme mit stärkerem Erbrechen reagierte, macht sich schuell geltend. Die ständige, Tag und Naclit fortgesetzte reichliche Zufulır von oft mit Wein und Kognak vermengtem Wasser oder NaCl-Lösung, sehr bald auch von Suppen, mag, wenn man den Sclılauch nicht für kurze Zeit abklemmt, für die Resorption nicht selır viel bedeutelı, da die Flüssigkeit schnell wieder abfließt, aber zugleich spült diese den Magen aus und entfernt die toxischen Massen - und zwar nicht nur aus dem Magen.

In den vorgesclirittenell Fällen der Atonie, die ich hier

Aus der Chirurgischen Abteilung des St. Josefstifis in Bremen.

\section{Zur Frage der Magen- und Darmentleerung bei atonischen Zuständen.}

Von Dr. Heinrich Gross, Oberarzt.

Auf Anregung hin von Anschütz (Kiel) - gelegentlich ciner Debatte über Peritonitisbehandlung auf der Bremer Tagung der nordwestd. Clirurgen 1912, wo jclı für Verwendung der Magenfistel eintrat, - habe ich damals bei drei Kranken nacheinander die ,Dauerausheberung" des Magens nach Westermann mittels des durch die Nase eingefülırteı Schlauches vorgenommen. Jedesmal war der funktionelle Erfolg nicht sehr befriedigend, jedenfalls nicht so, wie ich ihn wünschte, und dabei bei zwei - vielleicht besonders empfindlichen - Kranken der Akt, speziell die Prozedur der Einführung, trotz Kokainisierung des Naseneingangs so quäleıld, daß ich bei ihnen wieder meine Magenfistel anlegte. Wir sind ilır dann in immer gelıäufter Verwendung treu geblieben.

Fehlende Publikationen bzw. Aeußerungen außer von Kappis') (Kieler Klinik) ließjen mich glauben, daß auclı sonst die Methode wenig Anklang gefunden habe.

Nun wird sie von Grosser ${ }^{2}$ (Krankenhaus am Urban) auf Grund einer Erfahrung bei neun Fällen wicder warm empfohlen. Seine Ausführungen und eine erneute Durchsicht der Literatur, die mir die Berechtigung gibt, veranlassen mich, unter Mitteilung des bei uns so bewährten Verfahrens zu der wichtigen Frage der Dauerentleerung des Magens bei Atonio des Magens und des Darms Stellung zu nehmen. Hierzu glaube ich mich um so mehr berechtigt, als ich seit 1905 - wie ich nur nebenbei bemerke, nicht etwa, um eine Priorität geltend zu machen - zuerst vereinzelt, dalm systematisclı bei Störungen der Magen- und Darmmotilität die Dauerausheberung des Magens vornehme, und zwar mit Hilfe der obsoleten einfachen Magenfistel.

Sie wird, als selbständiger Akt natürlich in Lokalanassthesie, bei gefulltem Magen in der Medianlinie etwa in der Mitte zwischen Processus

1) Zbl. f. Chir. 1915. $-{ }^{2}$ ) Langenb. Arch. 103. zuilächst im Auge habe, lassen erst der kotige Geruch, dann eine oft sclir lange Permanenz galliger Beimengung vermuten, welclien Anteil mindestens der oberc Darmabschnitt - bei geöffneten Pylorus und Retroperistaltik — an der Füllung des Magens ninımt und welche Massen eventuell aus dem Darm zurïckströmen. I)ie ständige Entleerung des Magens, die den Zutritt erleichtert, in Verein mit der Saugwilkung des Hebers, gcstaltet diesen Rückfluß entschieden leiclıter. Die Magenfistel bedingt somit auch eine Entleerung des Darms. Ich bin geneigt, diese Funktion in ilırem EinfluB auf die Wiederkehr des normalen "Ionus mindestens als nicht gering einzuscliätzen.

Der Vergleiclı mit andereı Fällen, die keine Magenfistel benötigten, d. h. also solchen, wo die Atonie weniger ausgesprochen war, gibt dieser Bewertung eine gute Unterlage, eine bessere dic Beobachtung, daß sogar noch in der Rekonvaleszenz, bei längst rite licrgestellter Funktion, der Darnı auf eine zeitweilige Abkleminung des Sclilauches nicht selten Init deutlich verminderter Tätigkeit antwortet.

Diese Erfalırung nit dem Mageulheber liat uns veranlabst, die Darnfistel in der Indikation Schlanges zur Entleerung des toxisclien Darminhalts nicht inelır anzuwenden; ihre Wirkung crstreckt sich bei paralytischem Darm doch nur auf einen kleinen regionären Abschnitt und ist unseres Erachtens wesentlich geringer als dic unscres Magendarmhebers, wie wir sagen könnell, llachdem wir nıehrfach in einwandfreier Beobachtung festgestellt habell, daß er aus dem Darm ganz kopiöse Massen fortzuschaffen verinag; stammen letztere auch nur aus dem obersten Darmabschnitt, so wird doch durch ilıre Entfernung eiuc Entlastung auch der unteren Partien erreicht. Ebenso erkennt Grosser der ,,nasalen Drainage“ des Magens ,durch Fernwirkung" eine Saugwirkung auf die gefüllten Darmschlinger" " $\mathrm{zu}$.

Die Darmfistel, nicht selten gleiclızeitig mit der Magenfistel, findet ihre Anwendung bei uns llur nocl bei ausgesprochenen mechanischen Hindernissen, so durch Adhäsion oder Abknickung, wie z. B. bei eitriger Appendicitis als Folgeerscheinung, wo ich im Gegensatz zu mehrfach geäußerter Forderung der Relaparotomie stets mit ihr allein auskomme. 
Fincl bisher nicht behandelten Indikation hat die Darmfistel in drei Fällen genïgen müssen nach Operation der inkarzerierten Hernie, wo die Peristaltik bei anscheinend allzuschwer geschädigtem Darm nicht in Fluß kam; olme die lnkarzcrationsst $\in l l$; wicder aufzusuchen und zu eröffnen, haben wir jedesmal dic: Bcseitigung der Atonie crzielcn können.

Wir lassen den Magenschlanch fast immer bıs zıl völligen $B$ (scitigung der Infusion liegen, ihn als Ventil bemtzend, daw wieder geöffnet wird, sobald Stamung in Magendarmtraktus sich geltend macht; mit dem crsten Stıhlgang pflegen wir ihn abzıklemmen, erst voriibergehend, damı länger.

Wenn das Ansfließ3en von Magensaft mit Magcninlıalt seinerzeit dic ,einfache" Magenfistel in ibrer Bestimmung zur" da nernden Firnälırung mit vollen Recht in Mißkredit brachte und ihren Ersatz durch den Witzelschen Schrägkanal forderte, so branchen wir fïr unsere Aufgabe, den Mageninhalt für kurze Zeit nach außen zı leiten, dicse lästigen Konscquenzen nrht zu fürchten. Wohl haben wir sie bej Erweitermg des Magenloches ab'und zu erlcbt, aber ganz selten in Bildc des profusen Ausflusses; stets konnten wir durch einen Tupfer mit Heftpflasterstreifen, der dieWundränder neben dem Schlauch \%nsammenbrachte, leicht Ablilfe schaffen oder auch, wenn scinc: Aufgabe so wie so crledigt war, durch Entfernung des Schlauches.

Sich ausbildende - dam nicht selten unter Entwicklung kleinster, scharfrandiger Hantdefekte - stets ganz lokale Hikzeme heilten sclunell miter Pulvel- oder Salbenverband.

In Lanfe der Jalne ist unserc Magenfistel ein so selbst. vorständliches Requisit jeder Pcritonitisoperation gcwolden, dab sie sofort, anch wenn noch kein andauerndes Erbrechen oder Aufstolien besteht, von vornherein ins Auge gefasst und oft vor lnangriffualnme des eigentlichen Eingriffs angelegt wird. Eine alssgedehmte: Spannung der Bauchdecken, dic Magenatonie erwarten läßt, genügt, um uns die kleine Operation als notwendig crscheinen \%u lassen.

Bei tinem großen Laparotomiematerial habr. joll während der letzten 2 Jahre 47 mal die Magenfistel verwandt; sogar bei von vomucrein anssichtslosen Fälen, wie bei $z w \in i$, wo ich sie nnter Ablehmmng jedes weitcren Eingriffs anlegte; so blicb dem Kranken das quälende Brechcol trspant. mnd uns das leidige Ausspiilen dos Magens mittels des pec' os eingefülırten Schlauches.

Ohne Uebertreibung darf ich sagen, da $\$$ der Peritonitistod mit Magcnfistel und Daueraushebe. rung des Magens fiir den Kranken, wie für døn behandelnden Aryt solur viel von seincm schreoken (i)

Weitans das Gros der Anwendnng entfällt anf dic Peritoni tis (35 Fälle). Bei ihr habon wir erst dic L̀rfahrung gesanmuelt, dic: uns veranlaßte, dic: Magenfistel anch bei sonstigen atonischen Zuständen des Magens und Darns anzuwenden. So brim llens. Sobald hier ein stärkerer Fillungsgrad sich nur eben anzcigt, leitct dic: Eröffnung des Magens die operativen Mal3nahmon ein, sic; oft - rein physikaliseh - nanentlich bei Affektionen der mittlcren und oberen Bauchgegend, nicht unwowentlich erlcichternd.

Bei prall gefïllten Magen cutfällt dic notwendige und gefährliche Wutlecrmng durch den per os eingefïhrten Magensehlanich.

So finde ich in unserem Materia die ,präliminatorische“ Anwendung der Magenfistel (auBer bei ausgesprochener P.eritonitis) verzeiclmet $1 \mathrm{mal}$, bei akuter Pankreatitis, $1 \mathrm{mal}$ bei perforierendem Empyem der Gallenblase, 1 mal bei Schußverletzung des Colon transversium und der $\mathrm{V}$. cava und 4 mal bei mechanischem Ileus, darunter 1 mal bei Hernia incarcerata be-i eincr äußcrst erschöpften Frau, dic vorher auf die mehrmalige Ausspïlıng des Magens dureh deı behandelnden Arzt jedesmal einen Kollapszustand aufgewiesen hatte.

Nur einmal in dem bezeichneten Zeitraum hat die Magenfistcl cincr - meincs Erachtens absoluten - Indikation genïgt, bei akntester Magendilatation nach Exstirpation eines Typhlontımors. Frülıere Erfalırungen treten hinzı, um fïr uıs die Fordering geltend zu machen, bei jeder postoperativen Magenatonie nur ein-, höchstens zweimal den (per us eingefïhrten)
Magenschlauch 7.1 verwenden und dann sofort die Magenfistel anzıllegen.

Ilıren Platz füllt sie weiter voll und ganz aus bei Operationen des perforierten Magengeschwürs; in dem genamuten Zeitraum verdanke ich bei 4 Fällen 2 mal die schnelle Heilung wesentlich der Magenfistel.

Ein Feld der Betätigung scheint sie dagegen bei uns eingebiilist zu haben, seitden wir - seit $4^{1 / 2}$ Jahren - nur noch die einfar:lue, Gastroenterostomie (nach Petersen) anwenden. In friiheren Jithrn habe ich, was intcressieren dürte, die Magenfistel zweimal beim Girculus vitiosns nach Gastroenterostomia antecolica, einmal mit, einmal ohne Braunsche Anastomose, angelegt, und zwar von einem Schnitt ans neben der Laparotomiewunde. Der Errolg war sehr prompt; der (iallcmriickflul.3 sisticrte, nachdem die Magenfistel einmal -und zwar dort, wo die Enterostomie angelegt war - einen Tag und im zweiten Fall drei Tage in Funktion gewesen war. Da, wie ich glaubc, unsere Magenfistel eine Verwendung in weiteren Kreisen verdient, werde ich mich mit den folgenden Bemerkungen, wie auch den obigen, bezüglich der Technik an den ('hirurgie troibenden praktischen Arzt.

Die kleine Wunde wird in ihrer Hautfaszien- (und eventuell Muskcl-) Partie natürlich nicht genäht. Ein Stückchen Gaze bedeckt sie, das dırch Heftpflaster fixiert wird; eine durch lctzteres gefïhrte Sicherleitsnadel hält, den Gummischlauch fest.

Nacli lintfernung des Śchlauclıs werden dic: Wnndrändeı (lurch Heftpflasterstreifon aneinandergebracht.

1)ic: Hcilung elfolgt fast immer (s. o.) ganz glatt und unter Ausbildung cincr guten Narbe.

Frïher passierte es mir mehrmals, dab das Magenloch, weil es zn groß geworden, ektropionierte, soda B eine Nachoperation notwendig war. Ebenfalls frühcr glaubten wir, die Magennarbe revidiercn zu müssen, wozu Sekundäroperationen, wie nach Appendicitis, ja Gelegenhcit boten. Wir fanden auch in cincr, vielleicht der größtcn, Kategorit: mehr oder minder $f($ stc Adhäsionen, die wir damn trennten, bei der anderen stellten wir dagcgen schon nach Wochen die spontane Ablösung des Magens fest. Nienals aber hörten wir Klagen unserer Patienten über Magenbeschwerden, und so hat sich allmählich die Regel herausgebildct, ımr ausnahmsweise, so bei häßlicher Narbe, auch das innere Operationsterrain zu revidieren.

Um $\mathrm{mm}$ noch kurz anf den Ausgang der Ausführungen zurückzukommen, so bedarf es zır Erklärung, weshalb ichidas Westermannsche Verfahren für weniger vorteilhaft erachte, kaum noch des Hinweises, daB bei ihm gelegentliche Verletzungcul der Spciseröhrc mo des Magens vorkommen; sie, wie antch der - meiner, allerdings schr klcinen Erfahrung nach wenig angtnehme Akt der Finführmng mo auch des Liegenbleibens des Nasenschlauchs spiclen für dic Beurteilung keine so grobe Rolle. Eine sehr wesentlichc aber dcr Faktor, dab der Nasensschlaııch nur zwölf Stunden liegt und wälırend dieser Zeit kcine Flïssigkeits- bzw. Nahrungszufuhr crfolgt.

Dic Einpfehlung sollte cigentlich in Verkemung des Begriffs nicht von einer ,Daueraushcberung" splechen.

Dieser offenkundige Nachteil gegenüber meiner Magenfistcl läßt mich urteilen, daß obiges Verfahren besser für den Intemen sich eignet, dem es gegebenenfalls sicher vorzüglicho Dienste leisten wird, weniger für den Chirurgie treibenden Arzt. Ihm, dem der kleine Eingriff leicht zur Hand liegt, kann ich anf Grund einer 200 Fälle weit übersteigenden Erfahrung die ,einfache" Magenfistel nicht warm genng empfehlen. 